\title{
El cine documental como herramienta en la construcción de la memoria y el pasado reciente
}

\author{
Lidia G. Acuña ${ }^{1}$ \\ Universidad Nacional del Litoral
}

\section{Origen del cine documental, la cámara como herramienta}

El cine nació en Francia hacia 1894 cuando los hermanos Lumiére demuestran (filmando la salida de los obreros de la fábrica), los resultados obtenidos a partir de las investigaciones que hicieran en torno al kinestoscopio, que les permitió registrar el movimiento de las cosas. Así los Lumière son los verdaderos pioneros de un cine documental y testimonial. El registro documental es tan viejo como el cine, su evolución se encuentra ligado tanto a los desarrollos tecnológicos como a la renovación del género cinematográfico.

A comienzo del siglo XX se construye un lenguaje de registros sociales. En 1922 Flaherty concreta "Nanook" y unos años después Vertov hace "El hombre con la cámara", mientras Grierson es el fundador del "cine como creador de conciencia", este sociólogo escocés fundará la Escuela de Cine Documental Británica, concreta "Drifters" en 1929. A decir de Grierson: "yo lucho por el documental simplemente porque en el empleo de la materia verdadera está incluida también la posibilidad de hacer obra creadora". ${ }^{2}$

La línea de Grierson, con su documental social, influye en cineastas argentinos. Así se destaca los trabajos de Fernando Birri, en Santa Fe de los años '60, que crea la Escuela Documental de Santa Fe, en la Universidad Nacional del Litoral. Inaugurando la práctica de los llamados "fotodocumentales", verdaderas encuestas fotográficas y sociológicas. Realizando Tiré Dié (1956-58) considerada la primera encuesta social fílmica de América Latina y concretada por un colectivo de alumnos bajo la dirección de Birri. Luego el cine documental argentino sufrirá evoluciones, rupturas y cambios hasta la actual irrupción cuantitativa y cualitativa.

Mientras, desde mediados de siglo XX, la renovación epistemológica producida en las Ciencias Sociales es la que hace aparecer nuevos objetos de estudio adecuadamente vinculados a dimensiones socio-culturales. En una época en la que los medios de comunicación audiovisuales tienden a jugar un rol social cada vez más significativo nos parece importante dar a conocer nuestros aportes.

\section{Cine documental y pasado reciente}

Nuestro artículo se enmarca en la perspectiva de la Sociología de la cultura y la Historia social. Consideramos que el cine documental es un texto, una producción cultural sometida 
a la historia de los hechos y de las ideas. Una imagen de lo real que no sustituye a lo real sino que nos trae la experiencia de otros en el proceso de filmar. En nuestro caso la proliferación de relatos sobre el terrorismo de Estado en Argentina y sus dramáticas consecuencias establece la memoria como campo de conflictos.

Así, el cine documental político no busca hoy construir ficciones, sino intenta mirar de cerca las ficciones que sostienen la política en la realidad. La efervescencia testimonial coincide aquí, precisamente, con el auge del documental como género fílmico, destinado a su registro de discursos, testimonios, documentos, es decir la memoria como campo de operaciones de representaciones (Amado, 2005).

Este cine deriva de una evolución del documental en temáticas y modalidades en Argentina. En consecuencia es oportuno plantear la existencia de etapas en el desarrollo fílmico a partir de hechos y procesos que implican rupturas y cambios importantes en la historia de nuestro país: los años ‘ 60 , los ' 90 y el 2001 en la Argentina. Encontramos que en los años ' 60 las producciones tienen un acento en el cine político, llamado por algunos autores "filmografía revolucionaria en todo sentido" (Krieger, 2007), como "Los cuarenta cuartos", de Juan Oliva, Instituto de Cine, Santa Fe, 1962; "La Hora de los Hornos", de Solanas y Getino, Argentina, 1968 y "México, la revolución congelada", Raymundo Gleyzer , Argentina 1965, entre otras.

Luego desde mediados de los ' 90 hemos observado una irrupción del documental en el contexto de resurgimiento general del cine argentino. Se abordan diversas problemáticas, con renovadas formas de producción, en temáticas sobre por ejemplo la revisión de la historia y los hijos del proceso como: "Procesados" de Castro y otros, Santa Fe 1994; "Quién quiera oír que oiga", de Hudson, Rosario, 1998; "Veo, veo", Berta y otros, Rosario, 1996, "Historias Cotidianas (h)", de Habegger, Buenos Aires, 1999 y otras producciones.

Esta evolución audiovisual continuó y a partir del 2001 se multiplican las realizaciones con renovadas formas de producción: los documentales abordan otras problemáticas con nuevas perspectivas, como por ejemplo los materiales sobre fábricas recuperadas: "FASIMPAT", de Incalcaterra, Buenos Aires, 2004; "Grissinópoli”, de Doria, Buenos Aires, 2004; "Ocupar, resistir, producir”, Colectivo, Rosario, Santa Fe 2005 entre otros.

Prosiguiendo este camino de evolución, en la temática sobre la construcción de la memoria y la historia reciente, hemos encontrado desde el 2001: rupturas en las narraciones como el caso de Albertina Carri en "Los Rubios", Argentina 2004; Nicolás Prividera en "M", Buenos Aires, 2007, entre otros, ${ }^{3}$ que nos han abierto al tratamiento de estudios sobre el documental subjetivo. ${ }^{4}$

\section{Los hijos toman la cámara. Documentales en torno a la memoria y la identidad}

Centramos nuestra atención en los documentales que intentan reconstruir memorias del pasado reciente y observando cómo a partir del registro de discursos, testimonios, caminos, documentos e ideas de hijos de ex detenidos-desaparecidos durante la última dictadura militar en Argentina, se intenta construir memoria e identidad. 
En este artículo nos ocupamos de dos documentales: "Historias cotidianas (h)" y "Los Rubios". ${ }^{6}$ Estas producciones comparten el hecho de haber sido dirigidas por jóvenes realizadores, hijos, víctimas de la dictadura militar.

A partir de los aportes de Joel Candau y de Elizabeth Jelin, planteamos que hay un juego social de la memoria y la identidad, por ello la necesidad de recordar es una inquietud de individuos y grupos en busca de sí mismos. "La necesidad de recordar es pues real, aunque más no sea para no quedar desprovistos y vacíos” (Candau, 2001). Según Candau existe la necesidad de recordar para construir identidad individual y grupal. Pero también existe la necesidad de recordar y transmitir. En las sociedades modernas la transmisión de una parte creciente de la memoria está mediatizada. Así se plantean diferencias entre la transmisión histórica y la transmisión memorialista: la historia producida por los historiadores revela las formas del pasado. La transmisión memorialista está atravesada por el desorden de la pasión, de las emociones y de los afectos.

La construcción de la memoria no es lineal, a decir de Jelin (2002): "hay contradicciones, tensiones, silencios, conflictos, huecos y disyunciones, así como lugares de encuentro y aún de 'integración'. La realidad social es compleja, contradictoria, llena de tensiones y conflictos. La memoria no es una excepción".

Consideramos a la memoria como una construcción cultural donde la experiencia es vivida subjetivamente y culturalmente compartida y compartible. La memoria, entonces, se produce en tanto hay sujetos que comparten una cultura, en tanto hay agentes sociales que intentan "materializar" esos sentidos del pasado o de hechos recientes en diversos productos culturales que son concebidos como, o que se convierten en, vehículos de la memoria tales como los museos, libros, películas, entre otros.

Nos interesa interrogar a estos documentales como "vehículos" de la memoria. Entendemos que la memoria es una reconstrucción actualizada del pasado que actúa como un conjunto de estrategias que nos ayudan a definirnos ante el mundo. Planteamos trabajar las narraciones documentales como medio donde los hijos toman la cámara y la palabra.

Respecto a los documentales, en la temática que nos ocupa, hay una producción muy prolífera en Argentina, sobre todo en su variante testimonial, que elaboran y reelaboran distintas facetas de lo acontecido durante la última dictadura militar, sobre todo haciendo hincapié en la necesidad de recordar y colaborar en la construcción de la memoria de nuestra sociedad. Los films que se están analizando prefieren mostrar lo que está detrás de la evidencia, de lo inmediato, se trata de un cine que ayuda a pensar sobre nuestro pasado reciente y con fuertes marcas de sus realizadores que apuesta a la reflexión. Para analizar los textos fílmicos recurrimos a las modalidades de representación de Bill Nichols (1997). ${ }^{7}$

Nos interesa trabajar el aporte que estos films hacen a la construcción y reconstrucción de identidad, a partir de "mostrar", analizar y poner en agenda de debate el tema de los hijos de ex detenidos-desaparecidos en nuestro país, vemos como ellos se muestran, perciben e imaginan como miembros de un grupo produciendo diversas representaciones en cuanto a su pasado. 
De la gran diversidad de documentales alrededor de la temática de memoria-identidad y teniendo en cuenta nuestra selección de films, reflexionamos en torno a estas narraciones porque son, por un lado, realizaciones significativas a la constante búsqueda de memoria e identidad y, por otro, son ejemplos de modalidades de representación muy diferentes. También el cine documental resulta un constante aporte a la transmisión memorialista ya que son memorias narrativas que se incorporan a los trabajos de la memoria.

\section{4. "Historia Cotidianas (h)", testimonios de hijos}

En "Historias Cotidianas (h)" se elabora el relato a través del testimonio de seis jóvenes que quedaron marcados desde la infancia por la huella indeleble de la pérdida y/o ausencia de sus padres. Se trata de historias singulares, circunstancias particulares con más de un rasgo en común, pero que indisolublemente están integradas en la historia colectiva de nuestro país.

Su director, Andrés Habegger, es hijo de padres desaparecidos al igual que los jóvenes que relatan sus vivencias en el documental, esto no es un dato de menor importancia, ya que le otorga a la narración una fuerte impronta generacional. La historia del realizador no se representa en la película, pero en la forma de abordar el tema puede rastrearse la mirada que comparte con los otros hijos de desaparecidos. Todos eran niños entre 1976 y 1983 y se criaron sin uno o los dos padres, eso es lo que surge con más fuerza para el espectador, el dolor de esas pérdidas en la primera infancia y cómo cada uno recuerda las vivencias o ausencias de sus familiares. En esa época no se hablaba de "desaparecidos", todos imaginaban largos viajes, historias de detectives o villanos con espadas, y creían que algún día "sus padres iban a volver".

Los jóvenes que se presentan en esta película comparten una misma realidad, pero no todos piensan y sienten de la misma manera, esta diversidad enriquece la representación. Los narradores o protagonistas están ubicados delante de la cámara fija y se los escucha hablar durante largo tiempo de un pasado que se actualiza a través de la palabra, centrándose en el presente y evidenciando el horror de la dictadura a través de la ausencia de los padres y la mirada de los hijos hoy. Estos elementos se combinan y construyen un texto de modalidad de representación interactiva según Nichols, que lleva al espectador a una toma de conciencia en torno a los efectos que el terrorismo de Estado sigue teniendo en la vida de estos jóvenes en el presente.

El documental "Historias cotidianas (h)" apela al recurso de las entrevistas a los hijos como testigos que añaden el complemento de sus propias narraciones y representaciones en torno a los secuestros y desapariciones de sus padres, únicas voces que pueden describir el viraje histórico de esas acciones y elecciones, con sus consecuencias trágicas de separación y muerte (Amado, 2005).

En la obra de Habegger se revisa la historia, ensayando contarla desde espacios íntimos, o desde el afecto y las emociones junto a la conciencia social y la acción colectiva. Como muy bien lo resume el director "No quise subrayar lo político (...) busqué que la tragedia de la historia argentina se pudiese leer desde seis historias personales. Traté de ir desde lo individual a lo colectivo". ${ }^{8}$ 
En el largometraje dirigido por Habegger, vemos que hay una marcada intención de resaltar y profundizar los aspectos más íntimos e individuales de cada uno de los entrevistados, centrándose en las vivencias personales que permiten reconstruir la experiencia social. "Historias Cotidianas (h)" prioriza la historia individual-íntima de sus entrevistados, por sobre la historia política argentina, los HIJOS que dan su testimonio tienen prioridad en el discurso del film.

\section{5. "Los Rubios", documental subjetivo}

En el caso de Albertina Carri, directora de "Los Rubios", la búsqueda de las rutas de la memoria es íntima y personal. El film se presenta como la "memoria en acción" en sí mismo, es el laberinto que recorre su realizadora para reconstruir su historia el que se expone, y hay un claro planteo de separarse de otros discursos (institucionales, testimoniales y otras memorias). Este es un documental subjetivo que usa la voz en primera persona, registra la propia historia de Carri y a decir de Sartora (2007) es un documental con "la realizadora dentro de su film".

Es una obra que presenta la incesante búsqueda de su realizadora por rescatar una identidad que debe construirse a través de retazos y trozos de una historia que no se puede cerrar. Ella forma parte de una generación que tiene que aprender a convivir con los huecos y silencios entre el pasado y el presente, vacíos que intentan llenarse con recuerdos que muchas veces no se sabe si son tales o si se inventan. El argumento de la película no se detiene en la narración del pasado, sino que se ubica en un presente cargado de tensiones y conflictos que debe apostar a la memoria, recorrer los caminos y vericuetos en los que la mente o la imaginación quedan atrapadas al momento de recordar, el texto es una búsqueda en la que se transitan distintos senderos posibles en el campo de la memoria que posibilita reconstruir de alguna forma ese pasado cargado de ausencias. Albertina Carri expresa que "la película tiene momentos no de nostalgia pero sí de tristezas, emoción y dolor. Creo que eso lo cuenta. Lo que no quería era presentar ese dolor como irreparable. Yo de algún modo tenía que contar que yo me pongo a pensar en la memoria, en la ausencia, en el vacío, en las ficciones - que todo eso tienen-porque claramente a mí me sucedió esto. Si no cuento eso, es poco honesto. Entonces, sentía una clara obligación de contarlo, pero por otro lado no quería que contar eso fuese imposibilitar al espectador a pensar".

Por lo expuesto anteriormente podemos afirmar que este documental se construye a partir de una modalidad de representación reflexiva y subjetiva, centrando la atención del espectador no en el mundo histórico sino en la manera en que el mundo histórico es presentado, cómo se muestra y habla de la realidad en las imágenes.

En "Los Rubios" se superponen en este texto fílmico capas de sentido que se van multiplicando gracias al empleo y combinación de colores, el blanco y el negro, la animación de muñecos Playmobil, empleo de pantallas de televisores y computadoras, voz en off, presentación de una actriz que encarna a "Albertina" como protagonista, las pelucas rubias, entre otros. "Al realizar una película sobre la realización de una película -que de eso también se trata "Los Rubios" - se pone en descubierto el artificio (los mecanismos de construcción) y se comienza a jugar en tres niveles: realidad, ficción y documental. Como los espacios en 
blanco, los huecos de la memoria y el vacío, la narración de "Los Rubios" esta fragmentada y aparentemente desestructurada". ${ }^{10}$

Carri trabaja desafiando límites y discursos, e imponiendo su propia mirada de autorapersonaje. Así el aporte de "Los Rubios" plantea un desafío a la memoria y la identidad. A decir de Amado: "hay en 'Los Rubios' una especie de violencia teñida de melancolía contra la plenitud insospechada de una institución, la familia, y contra el mito de la escena idílica del pasado" (Amado, 2004).

El documental nos presenta a la protagonista en un doble juego de representación: la persona de Albertina Carri y una actriz que la encarna. El personaje principal es la directora, hay un uso constante de la técnica de la autorrepresentación, de la invención del pasado no conocido, construyendo así un texto reflexivo subjetivo en toda su magnitud. Carri deja planteado incluso un conflicto generacional entre los hijos y la generación de esos padres "heroicos". Según Ana Amado (2004) hay en "Los Rubios" una inocencia perversa de la generación de herederos. Esto construye un lenguaje que deposita en la estética de la memoria la clave de una subversión.

En síntesis en las dos obras trabajadas, los hijos se erigen como "testimonios" principales y determinantes en la reconstrucción del pasado reciente. Ellos suman el complemento de sus propias narraciones, así recordar es actualizar la huella que los hechos dejaron en la memoria privada.

Andrés Habegger en su perspectiva aporta las únicas voces testigos de secuestros y desapariciones. En sus testimonios interactivos los hijos toman la palabra frente a las consecuencias trágicas de separación y muerte. "Los Rubios", por un lado comparten el aspecto testimonialgeneracional de "Historias cotidianas (h)" pero por otro, Albertina Carri en su film representa una generación que confronta. Su voz cuestiona y se auto-representa como hija. "Los Rubios" apunta a la reflexión del espectador en torno a cómo el mundo histórico es representado, desorganizado y reconstruido en una forma particular el pasado.

Los dos documentales analizados son largometrajes, esta característica no es un dato menor ya que ello implica tareas de investigación y elaboración más profundas y complejas, además de contar con un equipo de realización que aborde los quehaceres específicos en cuanto al aspecto técnico y a la problemática abordada. Esto puede distinguirse de obras de años anteriores que son cortometrajes de 10, 15 minutos, en los primeros intentos de abordar el tema. ${ }^{11}$

Estas obras hacen coincidir aquí la efervescencia testimonial, con el auge del documental como género fílmico destinado al registro de discursos, testimonios, documentos, es decir la memoria-identidad como campo de operaciones de la representación.

En consecuencia, el camino recorrido desde los años ` 90 hace de la figura del documental en Argentina una forma fílmica recobrada, valorada y con producción en expansión. Esto se puede ver, por un lado, con su acrecentada presencia en muestras, festivales nacionales e internacionales y ganando espacios en cines así como en la televisión pública y privada del país y, por otro, en el creciente desarrollo del documental como objeto de estudio e investigación reconocido desde distintas disciplinas, donde se están desarrollando proyectos, seminarios, tesis, jornadas y publicaciones, que están construyendo un campo de investigación en progreso. 


\section{Notas}

${ }^{1}$ Directora del Proyecto CAI+D 2006: "El cine documental: la construcción de la memoria y las formas de representación del los procesos sociales", UNL. Directora del Centro de Investigaciones en Estudios Culturales, Educativos y Comunicacionales (CIECEC), Facultad de Humanidades y Ciencias, Universidad Nacional del Litoral, Santa Fe.

${ }^{2}$ Acuña, Lidia: "Memorias y representaciones de la inundación de Santa Fe 2003. Aportes de registros audiovisuales de personas mayores afectadas y excluidas en la crisis santafesina" (ponencia), IV Congreso de Politicas Sociales. Asociación Argentina de Políticas Sociales. Universidad Nacional del Litoral, 12 al 14 noviembre de 2008.

${ }^{3}$ Roqué, Maria: "Papá Iván” (Argentina, 2000).

${ }^{4} \mathrm{El}$ documental subjetivo se ha desarrollado en diversas temáticas como por ejemplo: "La televisión y yo" de Andrés Di Tella (Argentina, 2003) y "Fotografías" (Argentina, 2007) del mismo director.

${ }^{5}$ Habegger, Andrés director, "Historias Cotidianas (h)", duración 133 minutos, Buenos Aires, 1999. Guión: Lucía Puenzo y Andrés Habegger. Montaje: Laura Mattarollo. Fotografía y Cámara: Mariano Cúneo.

${ }^{6}$ Carri, Albertina directora, "Los Rubios", duración 89 minutos, Buenos Aires, 2003. Producción: Albertina Carri y Barry Ellsworth. Fotografía: Catalina Fernández. Cámara: Carmen Torres y Albertina Carri. Montaje: Alejandra Almirón. ${ }^{7}$ Este autor propone distinguir cuatro modalidades de representación: expositiva, texto que se dirige al espectador directamente, con intertítulos o voces que exponen una argumentación, por ejemplo acerca del mundo histórico, las imágenes sirven como ilustración. La de observación (que minimiza la presencia del realizador), documentales por ejemplo de carácter etnográfico. La interactiva la que el director y los actores sociales reconocen la presencia del otro abiertamente en la conversación y las acciones participativas, esta modalidad trabaja especialmente con entrevistas. Y la reflexiva, en la que el realizador dirige la atención del espectador hacia la forma, innovación de la obra. 
8 "Entrevista a Andrés Habegger" en diario La Capital, sábado 9 de junio de 2001, Rosario, Santa Fe.

${ }^{9}$ Mango, Agustín, Entrevista a Carri en www.subjetiva.com.ar

${ }^{10}$ Yolis, Ivonne: "Los Rubios", CINEISMO RECOMIENDA [www.cineismo. com].

${ }^{11}$ Duración a modo de ejemplo: 15 minutos "Procesados" (Santa Fe, 1993);

14 minutos "Laura” (Santa Fe, 2001), entre otros.

\section{Bibliografía}

Acuña, Lidia (2007): "El cine documental y los trabajos de la memoria" en Ríos, Guillermo (comp.): La cita secreta. Encuentros y desencuentros entre memoria y educación, AMSAFE, Santa Fe.

Amado, Ana (2004): "Órdenes de la memoria y desórdenes de la ficción" en Amado-Domínguez (comp.): Lazos de familia. Herencia, cuerpos, ficciones, Paidós, Buenos Aires.

(2005): "El documental político como herramienta de historia" en Revista Políticas de la Memoria № 5, CEDENCI, Buenos Aires.

Breschans, Jean (2004): El documental. La otra cara del cine. Paidós, Buenos Aires.

Candau, Joel (2001): Memoria e Identidad, Ediciones del Sol, Argentina.

Jelin, Elizabeth (2002): Los trabajos de la memoria. Siglo XXI, España.

Krieger, Clara (2007): "La experiencia del documental subjetivo en Argentina" en Cines al margen.

Nuevos modos de representación en el cine argentino contemporáneo, Libraria, Buenos Aires.

Moore, María y Paula Wolkowicz (2007): Cines al margen. Nuevos modos de representación en el cine argentino contemporáneo, Libraria, Buenos Aires.

Nichols, Bill (1997): La representación de la realidad. Cuestiones y conceptos sobre el documental, Paidós, España.

Sartora, Josefina: "Realizadores dentro de sus filmes. Una herramienta de denuncia y transformación" en Le Monde Diplomatique, octubre de 2007, Argentina. 